\title{
Fungi isolated from shoots showing ash dieback in the Wolica Nature Reserve in Poland and artificially inoculated seedlings with Hymenoscyphus fraxineus
}

\author{
Anna Żółciak ${ }^{1}$, Justyna Anna Nowakowska², Artur Pacia ${ }^{3}$, \\ Nenad Keča ${ }^{4}$, Tomasz Oszako \\ ${ }^{1}$ Forest Research Institute, Department of Forest Protection, Sękocin Stary, Braci Leśnej 3, 05-090 Raszyn, Poland, \\ phone: +48 227153822, email: A.Zolciak@ibles.waw.pl \\ ${ }^{2}$ Cardinal Stefan Wyszynski University in Warsaw, Faculty of Biology and Environmental Sciences, Wóycickiego 1/3, \\ 01-938 Warsaw, Poland \\ ${ }^{3}$ Forest District Chojnów, Pilawa, Klonowa 13, 05-532 Baniocha, Poland \\ ${ }^{4}$ University of Belgrade, Faculty of Forestry, Kneza Višeslava 1, 11030 Belgrade, Serbia \\ ${ }^{5}$ Bialystok University of Technology, Faculty of Forestry in Hajnówka, Piłsudskiego 8, 17-200 Hajnówka, Poland
}

\section{ABSTRACT}

Ash dieback caused by an alien, invasive fungus Hymenoscyphus fraxineus is a serious disease of European ash species in many parts in Europe. In Poland, the disease was recorded in the beginning of the 1990s. This study was performed in 2016-2017 with the aim to identify fungi isolated from ash shoots showing dieback symptoms in the Wolica Nature Reserve in Poland, as well as from shoots of two years-old ash seedlings inoculated with H. fraxineus in the greenhouse.

The most frequently isolated fungi from shoots of common ash (associated with the pathogenic fungus $H$. fraxineus) were identified on the basis of sequencing of the internal transcribed spacer region (ITS1) of fungal rDNA. In total, 19 fungal taxa were identified for ash shoots as follows: H. fraxineus, Fusarium avenaceum, Alternaria spp., Phomopsis oblonga, Diplodia mutila and other Phomopsis spp. The pathogen H. fraxineus was not found for all the shoots samples; one year after inoculation the aforementioned fungi and other species as: Alternaria alternata, Bionectria ochroleuca, Epicoccum nigrum, F. acuminatum, F. avenaceum, and Paraphaesphaeria neglecta were identified in inoculation point, as well as $H$. fraxineus. The same quantitative and qualitative changes of organisms were observed in the case of artificially colonised ash seedlings in the greenhouse, as well as in the shoots of adult ash trees in the forest.

\section{KEY WORDS}

bark necrosis, ash dieback, Fraxinus excelsior, Hymenoscyphus fraxineus, ITS1-F 


\section{INTRODUCTION}

The dieback symptoms of ash have been observed in Poland since 1992 (Stocki and Stocka 1999; Sierota 2001; Przybył 2002; Gil et al. 2017). Since then, it is known that the fungus Hymenoscyphus fraxineus (T. Kowalski) Baral, Queloz and Hosoya is responsible for a severe decline on all age classes of Fraxinus excelsior L. stands (Kowalski and Holdenrieder 2008, 2009; Kirisits et al. 2010). Ash dieback caused by $H$. fraxineus has been reported in numerous countries in Europe (Vasaitis and Enderle 2017; Enderle et al. 2017).

It is well documented that after the fungus $H$. fraxineus colonization of bark and wood tissues, phytotoxin viridiol is secreted causing dying of plant tissues (Andersson et al. 2010). After primary intensive development and killing of bark tissues, pathogen moves to the wood where it could be quickly substituted with other colonizers of dead tissues (Kowalski et al. 2016). Several species of fungi were found in necrotic tissues of shoots and stems of dying common ash trees (Przybył 2002; Kowalski and Kehr 1992; Kowalski and Łukomska 2005; Schumacher et al. 2007; Bakys et al. 2009; Kowalski and Bartnik 2010). Species observed on dead tissue of ash shoots represent a cosmopolitan fungal genus Alternaria (that includes saprobic and pathogenic species associated with a wide variety of substrates) (Woudenberg et al. 2013; Kowalski et al. 2016), genus Epicoccum (saprophytes or a weak pathogens or endophytes) (Khulbe et al. 1992; Bruton et al. 1993; Fávaro et al. 2012; Ristić et al. 2012), Diaporthe/Phomopsis (that includes pathogens, endophytes and saprobes) (Udayanga et al. 2011; Gomes et al. 2013; Kowalski et al. 2016), a genus Fusarium (that includes pathogens, but most species of this genus are harmless saprobes) (Summerell et al. 2010; Kowalski et al. 2016; Kowalski et al. 2017).

Study of the diversity of fungi in natural reserves is of wider interest because it is well known that more diverse ecosystems better cope with disturbing factors and alien invasive species. Very often, the molecular methods are applied in order to determine the fungalspecies with the help of universal primers, that is, 'ITS1' and 'ITS4' (Gardes and Bruns 1993; https://www.ncbi. nlm.nih.gov/). The above primers are complementary to the Internal Transcribed Sequences (ITS), and gained wide acceptance for work with fungal identification, because they amplify the highly variable ITS1 and ITS2 regions surrounding the 5.8S-coding sequence situated between the Small SubUnit-coding sequence (SSU) and the Large SubUnit-coding sequence (LSU) of the ribosomal operon (Martin and Rygiewicz 2005; Porras-Alfaro et al. 2014). Because of not exclusive power of distinction between fungal and plant rDNA amplification provided by 'ITS1' primer, the more accurate primer for fungal identification ('ITS1-F', Gardes and Bruns 1993), besides the 'ITS1' primer has been used in the present study.

The aim of this study was to identify fungal species associated with necrotic tissues of shoots of dying ash in the Wolica Nature Reserve in Poland and to compare results with data obtained after artificial inoculations of two-year-old ash seedlings with $H$. fraxineus.

\section{Material AND methods}

\section{Experiment I}

\section{Sampling in the stand}

In spring 2016, about thirty shoots, $4-8 \mathrm{~mm}$ in diameter with necrotic lesions were sampled from three common ash trees (F. excelsior) in the 26-year-old ash stand. The stand is located in compartment $374 \mathrm{c}$ in the Wolica Nature Reserve (52¹1'16.70”N, 2041'17.96”E). The phenomenon of ash dieback was investigated in this stand in 2012 and 2013, when the vitality of trees was very poor and many trees showed severe defoliation (Pacia et al. 2017).

In order to produce inocula for artificial inoculation, some fresh and healthy looking ash shoots were collected from mixed stands in the Chojnów Forest District.

\section{Isolation and identification of microorganisms from ash trees}

In the spring season in 2016, the living, symptomatic shoots (with lesions) collected in Wolica ash stand were cut into pieces of the length ca. 1-2 cm, and then sterilized in $90 \%$ ethanol $(1 \mathrm{~min}), 4 \% \mathrm{NaOCl}$ sodium hypochlorite (5 min) and again in 90\% ethanol (30 s) (Kowalski 2006). After drying them on a sterile filter paper and cutting down the top layer of bark, the wood was cut for pieces of ca. $5 \times 2 \times 2 \mathrm{~mm}$ and put on $2 \%$ 
malt-extract agar (MEA) medium (Merck, Germany) solidified in Petri plates. It was then incubated at $20^{\circ} \mathrm{C}$ in dark. In total, 60 pieces of symptomatic wood tissues were taken from thirty shoots.

The Petri plates with inoculum were incubated at $20^{\circ} \mathrm{C}$ in the dark and few days old growing colonies were transferred onto a new MEA media. The pure cultures of isolated fungi (22) were stored in Forest Research Institute and used for DNA extraction.

The $50 \mathrm{mg}$ of mycelium of each fungal species were homogenized in the presence of liquid nitrogen using a mortar and pestle. Total genomic DNA was extracted from mycelium with DNeasy Plant mini kit (Qiagen ${ }^{\circledR}$, Hilden, Germany) according to the manufacturer's instructions.
In order to identify the fungal species, the DNA of 22 fungal isolates were amplified by a conventional PCR approach with the use of the universal primers ITS1 (5' -TCC GTA GGT GAA CCT GCG G, White et al. 1990) or ITS1-F (5' -CTT GGT CAT TTA GAG GAA GTA A, Gardes and Bruns 1993) were used (Tab. 1). The $25 \mu$ PCR mix consisted of PCR buffer (10x), $25 \mathrm{mM} \mathrm{MgCl} 2,0.2 \mathrm{mM}$ dNTPs $1 \mu \mathrm{M}$ each primer, $1 \mathrm{U}$ of Taq polymerase, MQ water up to $25 \mu \mathrm{l}$ and $100 \mathrm{ng}$ of DNA. Cycling conditions were denaturation $95^{\circ} \mathrm{C} 5 \mathrm{~min}$ followed by 35 cycles of denaturation $94^{\circ} \mathrm{C}$ for $0.5 \mathrm{~min}$, annealing at $56^{\circ} \mathrm{C}$ for $0.5 \mathrm{~min}$ and extension $72^{\circ} \mathrm{C} 1 \mathrm{~min}$, and a final extension at $72^{\circ} \mathrm{C}$ for $7 \mathrm{~min}$ (Korabecna 2007, modified by Nowakowska). The PCR products of ITS region were separated by electrophore-

Table 1. Identification of 22 fungal isolates from dead tissues of ash shoots by using rDNA ITS sequencing

\begin{tabular}{|c|c|c|c|}
\hline Species isolated & $\begin{array}{l}\text { Primers used for } \\
\text { PCR amplification }\end{array}$ & $\begin{array}{l}\text { Reference number in NCBI } \\
\text { database and similarity (\%) }\end{array}$ & $\begin{array}{l}\text { No. of accession } \\
\text { in Genbank }\end{array}$ \\
\hline Alternaria alternata (Fr.) Keissl. ${ }^{1}$ & ITS1-F & KY609180 (99.0) & MF509751 \\
\hline Alternaria sp. $^{2}$ & ITS1-F & EU366278 (99.0) & MF509752 \\
\hline Bionectria ochroleuca (Schwein.) Schroers \& Samuels ${ }^{2}$ & ITS1-F & GU566253 (100.0) & MF509749 \\
\hline Boeremia exigua (Desm.) Aveskamp, Gruyter \& Verkley ${ }^{1}$ & ITS1 & MF599108 (100.0) & KX618484 \\
\hline \multirow{2}{*}{ Boeremia exigua var. exigua ${ }^{1}$} & \multirow{2}{*}{ ITS1 } & \multirow{2}{*}{ MF435055 (99.0) } & KX618485 \\
\hline & & & KX618486 \\
\hline Cryptosphaeria eunomia (Fr.) Fuckel ${ }^{1}$ & ITS1 & KY613993 (100.0) & KX618490 \\
\hline Cryptosphaeria eunomia $^{1}$ & ITS1 & KY613993 (100.0) & KX618491 \\
\hline Diaporthe eres Nitschke $^{2}$ & ITS1-F & EU571099 (198.0) & MF509750 \\
\hline Diplodia mutila (Fr.) Mont. ${ }^{1}$ & ITS1 & KF766158 (100.0) & KX618487 \\
\hline Diplodia mutila (Fr.) Mont. ${ }^{1}$ & ITS1 & KF766158 (100.0) & KX618488 \\
\hline Epicoccum nigrum Link $^{2}$ & ITS1-F & KR094452 (100.0) & MF509753 \\
\hline 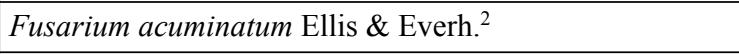 & ITS1-F & KJ737377 (100.0) & MF509746 \\
\hline Fusarium avenaceum (Fr.) Sacc. $^{2}$ & ITS1-F & HG936695 (99.0) & MF509747 \\
\hline Fusarium oxysporum Schlechtend. ${ }^{1}$ & ITS1 & AB470850 (100.0) & KX618492 \\
\hline Hymenoscyphus fraxineus Baral. et al. ${ }^{1,{ }^{*}}$ & ITS1 & HM193468.1 (100.0) & KY613994 \\
\hline Paraphaesphaeria neglecta Verkley, Riccioni \& Stielow ${ }^{2}$ & ITS1-F & JX496164 (100.0) & MF509754 \\
\hline Phomopsis oblonga (Desm.) Traverso ${ }^{1}$ & ITS1 & KR909214.1 (100.0) & KX618489 \\
\hline Phomopsis sp. ${ }^{2}$ & ITS1-F & EU571102 (99.0) & MF509748 \\
\hline Unidentified Ascomycota $^{1}$ & ITS1 & JQ765657 (99.0) & KX618493 \\
\hline Unidentified Ascomycota $^{2}$ & ITS1 & JQ765657 (99.0) & KX618494 \\
\hline Unidentified Pleosporales $^{1}$ & ITS1 & KC311498 (99.0) & KX618495 \\
\hline
\end{tabular}

1 - isolated from dying ash shoots taken from the ash trees in the Wolica Nature Reserve; 2 - isolated from 2-year-old dead ash seedlings one year after the inoculation of $H$. fraxineus.

* Under the rules for the naming of fungi with pleomorphic life-cycles adopted in 2011, the nomenclaturally correct name for the fungus causing ash dieback in Europe is determined to be Hymenoscyphus fraxineus, with the basionym Chalara fraxinea. 
sis on $1.5 \%$ agarose gels. Prior to sequencing, the amplicons were purified with QIAquick PCR Purification Kit (Qiagen Ltd), according to the manufacturer's protocol. Sequencing was performed using the BigDye Terminal Cycle Sequencing Kit (AB Applied Biosystems, CA, USA) in ABI 3500 Genetic Analyzer (Life Technologi$\mathrm{es}^{\mathrm{TM}}$, USA). The retrieved sequences were identified by comparison with sequences deposed in NCBI database using BLAST (Basic Local Alignment Search Tool, accessed November 8, 2017).

All the selected sequences based on the analyses of the ITS1 rDNA region were compared by aligning them with an online version of Multiple Sequence Alignment (MSA) with Clustal Omega program v. 1.2.4 (Sievers et al. 2011). To better illustrate the relationship between the identified isolates, the phylogenetic NeighbourJoining tree has been constructed in MAFFT v. 7 with bootstrap 100, threshold $8.4 \mathrm{e}^{-11}$ (https://mafft.cbrc.jp/ alignment/server/).

\section{Experiment II}

\section{Plant material}

The experiment was performed in the greenhouse of the Forest Research Institute (IBL, Sękocin Stary, Poland). Sixty two-year-old European ash seedlings were planted in 11 pots filled with a 1:1 (v:v) peat: perlite mixture at the beginning of the vegetation in May 2016. The temperature ca. $22^{\circ} \mathrm{C}$ and relative humidity $65 \%$ $\pm 5 \%$ was controlled automatically by the computer software and were shaded when the light intensity exceeded $50 \mathrm{klx}$. Plants were irrigated manually with tap water once a day.

\section{Inoculation of seedlings}

In September 2016, twenty ash seedlings were inoculated at the base of stems $(5-10 \mathrm{~cm}$ above the soil level). The control variant consisted of forty ash seedlings: twenty wounded in the same way as described above and another twenty ones not inoculated and not wounded. In order to obtain the inocula, the healthy ash branches were cut into small pieces autoclaved and placed on the surface of the $H$. fraxineus four-week-old pure cultures and kept for 4 weeks to let them overgrow with fungus. Then, the inocula were placed under the cut bark in $T$ shape and sealed with Parafilm (SigmaAldrich, Taufkirchen, Germany).

\section{Isolation and identification of microorganisms} from seedlings

In September 2017 (one year after inoculation), the reisolation from 20 dead ash seedlings inoculated with $H$. fraxineus were performed from around the inoculation points and 120 pieces of wood were placed on $2 \%$ maltextract agar (MEA) medium (Merck, Germany). The obtained pure cultures of fungi were identified in both ways morphologically at the genus level and molecularly (according to the method described in the Experiment I) at the level of species.

\section{Results}

From shoots of ash trees in Wolica stand, the following fungi species were identified: Phomopsis oblonga (21.7\% of all), Diplodia mutila (20.5\%), Boeremia exigua syn. Boeremia exigua var. exigua (20.9\%), Cryptosphaeria eunomia (8.6\%), Fusarium oxysporum (1.6\%) and Ascomycota sp. (13.8\%), Pleosporales sp. (8.3\%) and Hymenoscyphus fraxinues (4.6\%) (Tab. 1). The phylogenetic alignment based on the NJ tree confirmed the close relationships between ITS1 rDNA sequences of Fusarium isolates, and, for example, Fusarium sp. (accession numbers MF509746, MF50974647 and KX618492), and Bionectra ochroleuca (MF5097749) (Fig. 1). The latest four isolates were characterised by very low genetic distance (0.038). Polymorphic sites revealed between positions 0-994 bp of the studied ITS1 regions clearly shows the differences between all the investigated species (Suppl. fig. in electronic ver.).

In the experiment in greenhouse, $100 \%$ of the seedlings inoculated with $H$. fraxineus were dead (already eight months after inoculation). From ash seedlings, $H$. fraxineus was identified in only $2.4 \%$ of the obtained cultures. Among the obtained isolates dominated, Fusarium species were dominated with $38.8 \%$ (F. avenaceum $-33.1 \%$ and $F$. acuminatum $-5.5 \%$ ), while Alternaria species with the frequency of $28.7 \%$. Phomopsis spp., including Diplodia eres, were third most frequently observed colonizers with the frequency of $17.7 \%$, while the other unidentified species were from phylum Ascomycota participated with 7.9\% in total isolations. Bionectria ochroleuca, Paraphaeshaeria neglecta and E. nigrum were observed at frequencies $4 \%$, 0.4 and $0.1 \%$, respectively. 




Figure 1. NJ tree derived from the analysis of the ITS dataset. For each isolate, the number of accession to the GenBank and the distance representing the nucleotide substitution values were given

\section{Discussion}

Do the present studies show the succession of fungi colonizing ash tissues? We did not apply different time of sampling (initial necrosis, advanced necrosis and dead shoots); however, we noticed a clear difference after a year of the experiment. Instead of inoculated pathogenic anamorph Chalara fraxinea, we isolated many other fungal species. The reason for this is probably that the fungus $H$. fraxineus is a primary pathogen killing healthy tissues, mainly to its ability of viridol production, which is toxic to ash plants (Grad et al. 2009; Andersson et al. 2010). However, later, the fungus is losing the competition with other decomposing fungi being more successful and taking over their domination in dead tissues. We noticed that symptomatic ash shoots colonized by other plant pathogens, as well as by endophytes and saprobes.
In this work, the fungal species were identified based on the analysis of ITS1 sequences of the rDNA. Identification of fungi from, for example, Fusarium and Alternaria genera based only on analysis of ITS sequences are very problematic, nevertheless the ITS1 region is commonly used as the first step in molecular identification of fungi (Toju et al. 2012). It has been demonstrated that this fragment of internal transcribed spacer of fungal ribosomal RNA identifies the ascomycetous, basidiomycetous, and zygomycetous fungi to the species level (Glass and Donaldson 1995). Other genes (e.g., ACT, $\beta \mathrm{T}$, TEF1- $\alpha, \mathrm{CAL}$ ) can also be studied for a precise identification of fungal species. In many studies, the use of ITS sequence data together with protein-coding genetic data has become the normal practice for fungal identification (Korabecna 2007; Duong et al. 2012). According to Porras-Alfaro et al. (2014), the sequencing of the LSU region in many fungal spe- 
cies gives very similar results of the comparison based on MSA with the study based on the entire ITS region (ITS1 plus 5.8S rRNA plus ITS2). In some cases, the phylogenetic analyses of the ITS2-LSU sequences have revealed that the morphologically similar isolates represent a complex of the cryptic species (Doung et al. 2012). Hence, our molecular analysis with the general set of primers, that is, ITS1 and ITS1-F can be considered as a preliminary attempt of identification, prior to the future focus on other genes, that is, ACT, $\beta-\mathrm{T}, \mathrm{CAL}$ or TEF1- $\alpha$, which permit more accurate identification of fungi from, for example, Fusarium and Alternaria genera.

Nevertheless, we managed to describe the fungal community structure in the declining shoots of ash trees in the Wolica Nature Reserve in Poland and we got similar results in the greenhouse experiment, while inoculating shoots with $H$. fraxineus and performing re-isolation tests after a year. Based on the comparison of ITS1 sequences, the results of this survey revealed 19 fungal taxa associated with ash shoots showing dieback. This is the valuable point of this research. Moreover, our findings confirmed the occurrence of fungi in symptomatic shoots of $F$. excelsior published earlier by many scientists. According to Boudier (1994), Phoma exigua (Boeremia exigua) can cause brown spotting on 1- and 2-year-old shoots of European ash seedling. Next to Hysterographium fraxini, P. exigua have been considered to be involved in serious decline, in combination with abiotic factors (Grzywacz 1995; Przybył 2001). Boeremia exigua (synonym B. exigua var. exigua) is an ubiquitous soil borne saprobe, weak pathogen or wound parasite. Associated with stem and leaf lesions of a wide range of host plants and with rotting fleshy roots and tubers, often causing distinct symptoms such as leaf spots, stem lesions, damping off, dieback, root rots and tuber rots. Our findings are also compatible with Kowalski and Kehr (1992) research, who presented population of endophytic fungi on ash branches with the most characteristic fungi from Coniothyrium, Pezicula and Chalara genus. They found the same species of fungi as we did like Alternaria alternata, Diplodia mutila, and Phomopsis sp., but also Cladosporium cladosporioides, Cytospora ambiens and Phomopsis controversa. The species Phomopsis scobina was isolated from dead or dying top parts of shoots (Kowalski and Łukomska 2005), while from cankers also C. am- biens, $P$. controversa, and P. scobina. Przybył (2001) noticed that $P$. controversa, $P$. scobina, $C$. ambiens, $A$. alternata and $D$. mutila are the fungi associated with both dead and living 1-2-year-old trees showing necrosis of their tops, which was also true in our case for $A$. alternata and D. mutila.

Fungi belonging to Phomopsis and Cytospora genus are pathogens of weakness and are often present in dying shoots (Przybył 2002; Cech 2005; Kowalski and Łukomska 2005; Barklund 2006; Gomes et al. 2013). D. mutila (telemorph: Botryosphaeria stevensii) is a widespread pathogen in the world occurring mainly on Quercus, Juniperus, and Pinus (Vajna 1986; Luque and Girbal 1989; El-Badri et al. 1998; Stanosz et al. 1998; Mohali and Encinas 2001). Aforementioned fungi can exist in oak shoots as endophytes, but can also become pathogenic when the host is weakened by abiotic factors (Collado et al. 1999; Ragazzi et al. 2001). Przybył (2003) and Kowalski et al. (2017) proved pathogenicity of D. mutila. According to Kowalski et al. (2017), D. mutila and Cytospora pruinosa are less pathogenic than $H$. fraxineus, but more than the other fungi. Species like Diaporthe eres, F. avenaceum, F. solani and $F$. lateritium are considered to be the least pathogenic.

The occurrence of Epicoccum is also not so simple and obvious case in respect of its pathogenicity. Namely, this genus could be a saprophyte, a weak pathogen of rapeseed seeds and roots as well as sorghum seeds and seedlings, an opportunistic pathogen of melon, cucumber, tomato, apple and pear fruit or sugarcane endophyte (Khulbe et al. 1992). Seed-borne infection, pathogenic importance and control of Epicoccum nigrum Ehrenb, ex Schlecht. In rape seed (Brassica napus L.), these were thoroughly described by Khulbe et al. (1992), Bruton et al. (1993), Fávaro et al. (2012) and Ristić et al. (2012).

Tulik et al. (2017) developed the hypothesis that ash trees affected by $H$. fraxineus causing ash dieback could exhibit a reduced vessel size and density along the trunk, as well as a lowered width of annual wood rings, leading to the weakening of water transport towards the crown. As the consequence, shoots that are dying result in infection by aforementioned species of fungi genus Phomopsis, Diplodia, Fusicoccum, Diaporthe, Cytospora and others. In such a way, the phenomenon of fungi succession is initiated first in living, later in dead ash shoots. This observation proved to be a rapid 
stepping down of $H$. fraxineus - the primary cause of ash dieback, being replaced by other fungi colonizing ash tissues.

From this point of view, the knowledge of the distribution of pathogenic fungal species associated with $F$. excelsior suffering from ash-dieback phenomenon can be very useful in forest tree management and diversity conservation programs. In both experiments (in the stand and in the greenhouse), we observed no crucial difference between the fungal species isolated from young shoots (naturally infected in the ash stand and seedlings inoculated with $H$. fraxineus in the greenhouse). However, we did not check the occurrence of the aforementioned fungi in living plant tissues. We believed that those fungi come after infection by $H$. fraxineus because control plants were healthy. Nevertheless, it is possible that some of those fungi could live as endophytes, but it was not the purpose of this study.

\section{Conclusion}

After ash shoot infection by $H$. fraxineus, the succession of other species of fungi was observed as well in natural (Wolica Reserve) as in control conditions (greenhouse).

Especially in fungi, which are less successful in colonizing living tissues, start to overtake wood of ash shoots previously killed by $H$. fraxineus.

\section{Acknowledgements}

Authors thank Małgorzata Gorzkowska for the ITS1 rDNA analysis, and IBL funds supporting 3 months stay of Prof. Nenad Keča in the Department of Forest Protection in Sękocin Stary.

The present research was supported by the Ministry of Science and Higher Education of Poland as the part of project no. 240325 .

\section{References}

Andersson, P.F., Johansson, S.B.K., Stenlid, J., Broberg, A. 2010. Isolation, identification and necrotic activity of viridiol from Chalara fraxinea, the fungus responsible for dieback of ash. Forest Pathology, 40, 43-46. DOI: 10.1111/j.1439-0329.2009.00605.x

Bakys, R., Vasaitis, R., Barklund, P., Thomsen, I.M., Stenlid, J. 2009. Occurrence and pathogenicity of fungi in necrotic and non-symptomatic shoots of declining common ash (Fraxinus excelsior) in Sweden. European Journal of Forest Research, $128,51-60$.

Barklund, P. 2006. Unknow fungus causes dieback of ash shoots (in Swedish). Skogseko, 3, 10-11.

Boudier, B. 1994. The canker of ash seedlings (in French). Phytoma, La Défense des Végétaux, 461, 35-36.

Bruton, B.D., Redlin, S.C., Collins, J.K., Sams, C.E. 1993. Postharvest decay of cantaloupe caused by Epicoccum nigrum. Plant Disease, 77, 1060-1062.

Cech, L.T. 2006. Auffelende Schadfaktoren an Waldbaeumen im Jahr 2005. Forstschutz Aktuell, 35, 6-7.

Collado, J., Platas, G., Gonzalews, I., Pelaez, F. 1999. Geographical and seasonal influences on the distribution of fungal endophytes in Quercus ilex. New Phytologist, 144, 525-532.

Duong, T.A., De Beer, Z.W., Wingfield, B.D., Wingfield, M.J. 2012. Phylogeny and taxonomy of species in the Grosmannia serpens complex. Mycologia, 104, 715-732.

El-Badri, N., Abadie, M. 1999. Contribution to the ultrastructural study of Diplodia mutila (Fri.) Mont. implicated in the decline process of the cork oak Quercus suber L., in Morocco. IOBC/WPRS Bulletin, 22 (3), 13-18.

Enderle, R., Pliura, A., Vasaitis, R. (eds.). 2017. Advances in ash dieback research, - and some other invasive diseases of trees. Baltic Forestry, 23 (1), 1-333.

Fávaro, L.C. de Lima, Sebastianes, F.L. de Souza, Araújo, W.L. 2012. Epicoccum nigrum P16, a sugarcane endophyte, produces antifungal compounds and induces root growth. PLoS ONE, 7, e36826. DOI: 10.1371/journal.pone.0036826

Gardes, M., Bruns, T.D. 1993. ITS primers with enhanced specificity for basidiomycetes application to the identification of mycorrhizae and rusts. Molecular Ecology, 2, 113-118. DOI: 10.1111/j.1365294X.1993.tb00005.x

Gil, W., Kowalski, T., Kraj, W., Zachara, T., Łukaszewicz, J., Paluch, R., Nowakowska, J.A., Oszako, T. 
2017. Ash dieback in Poland - history of the phenomenon and possibilities of its limitation. In: Dieback of European ash (Fraxinus spp.). Consequences and guidelines for sustainable management (eds.: R. Vasaitis, R. Enderle), Swedish University of Agricultural Sciences, Uppsala, Sweden, 176-184.

Glass, N.L., Donaldson, G.C. 1995. Development of primer sets designed for use with the PCR to amplify conserved genes from filamentous ascomycetes. Applied Environmental Microbiology, 61, 1323-1330.

Gomes, R.R., Glienke, C., Videira, S.I.R., Lombard, L., Groenewald, J.Z., Crous, P.W. 2013. Diaporthe: a genus of endophytic, saprobic and plant pathogenic fungi. Persoonia, 31, 1-41. DOI: 10.3767/003158513X666844

Grad, B., Kowalski, T., Kraj, W. 2009. Studies on secondary metabolite produced by Chalara fraxinea and its phytotoxic influence on Fraxinus excelsior. Phytopathologia Polonica, 54, 61-69.

Grzywacz, A. 1995. Ważniejsze choroby infekcyjne. In: Jesion wyniosły Fraxinus excelsior L. (ed.: W. Bugała.). Wyd. Sorus, Poznań-Kórnik, 371-415.

Khulbe, R.D., Dhyani, A.P., Sati, M.C. 1992. Seedborne Infection, pathogenic importance and control of Epicoccum nigrum Ehrenb, ex Schlecht. in rape seed (Brassica napus L.) in Kumaun Hills, U.P., India. Proceedings of the Indian National Science Academy, B58 (2/3), 135-140.

Kirisits, T., Matlakova, M., Mottinger-Kroupa, S., Cech, T.L., Halmschlager, E. 2010. Chalara fraxinea associated with dieback of narrow-leafed ash (Fraxinus angustifolia). Plant Pathology, 59, 411.

Korabecna, M. 2007. The variability in the fungal ribosomal DNA (ITS1, ITS2, and 5.8 S rRNA Gene): its biological meaning and application in medical mycology. Communicating Current Research and Educational Topics and Trends in Applied Microbiology, 105, 783-787.

Kowalski, T. 2006. Chalara fraxinea sp. nov. associated with dieback of ash (Fraxinus excelsior) in Poland. Forest Pathology, 36, 264-270. DOI: 10.1111/j.14390329.2006.00453.x

Kowalski, T., Bartnik, C. 2010. Morphological variation in colonies of Chalara fraxinea isolated from ash (Fraxinus excelsior L.) stems with symptoms of dieback and effects of temperature on colony growth and structure. Acta Agrobotanica, 63, 99-106.
Kowalski, T., Bilański, P., Kraj, W. 2017. Pathogenicity of fungi associated with ash dieback towards Fraxinus excelsior. Plant Pathology, 66 (8), 1228-1238. DOI: $10.1111 /$ ppa.12667

Kowalski, T., Holdenrieder, O. 2008. Eine neue Pilzkrankheit an Esche in Europa. Schweizerische Zeitschrift für Forstwesen, 3, 45-50.

Kowalski, T., Holdenrieder, O. 2009. Pathogenicity of Chalara fraxinea. Forest Pathology, 39, 1-7.

Kowalski, T., Kehr, R.D. 1992. Endophytic fungal colonization of branch bases in several forest tree species. Sydowia, 44, 137-168.

Kowalski, T., Kraj, W., Bednarz, B. 2016. Fungi on stems and twigs in initial and advanced stages of dieback of European ash (Fraxinus excelsior) in Poland. European Journal of Forest Research, 135, 565-579.

Kowalski, T., Łukomska, A. 2005. Badania nad zamieraniem jesionu (Fraxinus excelsior L.) w drzewostanach Nadleśnictwa Włoszczowa. Acta Agrobotanica, 59, 429-440.

Luque, J., Girbal, J. 1989. Dieback of cork oak (Quercus suber) in Catalonia (NE Spain) caused by Botryosphaeria stevensii. European Journal of Forest Pathology, 19, 7-13.

Martin, K.J., Rygiewicz, P.T. 2005. Fungal-specific PCR primers developed for analysis of the ITS region of environmental DNA extracts. BMC Microbiology, 5 (1), 28. DOI: 10.1186/1471-2180-5-28

Mohali, S., Encinas, O. 2001. Association of Diplodia mutila with blue stain of Caribbean pine in Venezuela. Forest Pathology, 31, 187-189.

Pacia, A., Nowakowska, J.A., Tkaczyk, M., Sikora, K., Tereba, A., Borys, M., Milenković, I., Pszczółkowska, A., Okorski, A., Oszako, T. 2017. Common ash stand affected by ash dieback in the Wolica Nature Reserve in Poland. Baltic Forestry, 23(1), 183-197.

Porras-Alfaro, A., Liu, K.L., Kuske, C.R., Xie, G. 2014. From genus to phylum: large-subunit and internal transcribed spacer rRNA operon regions show similar classification accuracies influenced by database composition. Applied and Environmental Microbiology, 80 (3), 829-840.

Przybył, K. 2001. Grzyby występujące w wierzchołkowej części pędów jesionu wyniosłego wykazujących zmiany nekrotyczne. Materiały z V Konferencji 
Sekcji Chorób Roślin Drzewiastych Polskiego Towarzystwa Fitopatologicznego. Etiologia i objawy chorób grzybowych oraz ich występowanie i szkodliwość w ekosystemach leśnych. Poznań-Błażejewko, 29 maja-1 czerwca 2001, 32-41.

Przybył, K. 2002. Fungi associated with necrotic apical parts of Fraxinus excelsior shoots. Forest Pathology, 32, 387-394.

Przybył, K. 2003. Effect of Pseudomonas spp. on inoculation of young plants of Fraxinus excelsior stem with Diplodia mutila. Dendrobiology, 50, 29-32.

Ragazzi, A., Morrica, S., Capretti, P., Dellavalle, I., Mancini, F., Turco, E. 2001. Endophitic fungi in Quercus cerris: isolation frequency in relation to phenological phase, tree health and the organ affected. Phytopathologia Mediterranea, 40, 165-171.

Ristić, D., Stanković, I., Vučurović, A., Berenji, J., Krnjajić, S., Krstić, B., Bulajić, A. 2012. Epicoccum nigrum novi patogen semena sirka u Srbiji. Ratarstvo i povrtarstvo, 49, 160-166.

Schumacher, J., Wulf, A., Leonhard, S. 2007. Erster Nachweis von Chalara fraxinea $\mathrm{T}$. Kowalski sp. nov. in Deutschland - ein Verursacher neuartiger Schäden an Eschen. Nachrichtenblatt des Deutschen Pflanzenschutzdienstes, 59, 121-123.

Sierota, Z. 2001. Choroby lasu. Choroby lasu? Centrum Informacyjne Lasów Państwowych, 1-156. ISBN 83-88478-18-4.

Sievers, F., Wilm, A., Dineen, D., Gibson, T.J. Karphus, K., Li, W, Lopez, R., Mc William, H., Remmert, M., Söding, J., Thompson, J.D., Higgins, D.G. 2011. Fast, scalable generation of high-quality protein multiple sequence alignments using Clustal Omega. Molecular Systems Biology, 7, 539. DOI: 10.1038/msb.2011.75

Stanosz, G.R., Swart, W.J., Smith, D.R. 1998. Similarity between fungi identified as Diplodia pinea f. sp. cupressi in Israel and Botryosphaeria stevensii or Diplodia mutila on Juniperus in the United
States. European Journal of Forest Pathology, 28, 33-42.

Stocki, J., Stocka, T. 1999. Przyczyny zamierania drzew i drzewostanów jesionowych. Biblioteczka leśniczego, 118. Wyd. Świat, Warszawa, 3-11.

Summerell, B.A., Laurence, M.H., Liew, E.C., Leslie, J.F. 2010. Biogeography and phylogeography of Fusarium: a review. Fungal Diversity, 44, 3-13. DOI: 10.1007/s13225-010-0060-2

Toju, H., Tanabe, A.S., Yamamoto, S., Sato, H. 2012. High-coverage ITS primers for the DNA-based identification of ascomycetes and basidiomycetes in environmental samples. PloS ONE, 7, e40863.

Tulik, M., Zakrzewski, J., Adamczyk, J., Tereba, A., Yaman, B., Nowakowska, J.A. 2017. Anatomical and genetic aspects of ash dieback: a look at the wood structure. iForest-Biogeosciences and Forestry, 10, 522-528. DOI: 10.3832/ifor2080-010

Udayanga, D. 2011. The genus Phomopsis: biology, applications, species concepts and names of common phytopathogens. Fungal Diversity, 50, 189-225. DOI: $10.1007 / \mathrm{s} 13225-011-0126-9$

Vajna, L. 1986. Branch canker and dieback of sessile oak (Quercus petrea) in Hungary caused by Diplodia mutila. European Journal of Forest Pathology, 16, 223-229.

Vasaitis, R., Enderle, R. 2017. Dieback of European ash (Fraxinus spp.) - consequences and guidelines for sustainable management. The Report on European Cooperation in Science \&Technology (COST). Action FP1103 FRAXBACK. Uppsala, 1-229.

White, T.J., Bruns, T., Lee, S., Taylor, J. 1990. Amplification and direct sequencing of fungal ribosomal RNA genes for phylogenetics,. In: PCR protocols: A guide to methods and amplifications (eds.: M.A Innis et al.). Academic Press, New York, 315-322.

Woudenberg, J.H., Groenewald, J.Z., Binder, M., Crous, P.W. 2013. Alternaria redefined. Studies in Mycology, 75, 171-212. DOI: 10.3114/sim0015 
Supplementary Figure. Polymorphism sites in the ITS regions of the 21 investigated isolates. Numbers at the end of column indicate the relative positions in the alignments. Sites indicated by * are conservative in all isolates, while sites which differ are indicated with '-'.

\section{CLUSTAL Omega(1.2.4) multiple sequence alignment}

Cryptosphaeria_eunomia_KX618490 Cryptosphaeria_eunomia_KX618491

Phomopsis sp. MF509748

Diaporthe_eres_MF509750

Phomopsis oblonga KX618489

Bionectriā_ochroleuca_MF509749

Fusarium oxysporum KX'18492

Fusarium_acumnatum_MF509746

Fusarium avenaceum MF509747

Hymenoscyphus_fraxineus_KY 613994

Diplodia_mutī̄a_KX618487

Diplodia mutila KX618488

Paraphaeosphaería_neglecta_MF509754

Alternaria alternāta MF509751

Alternaria_sp._MF509752

Pleosporales_sp. KX618495

Ascomycota_sp._KX618493

Ascomycota_sp._KX618494

Epicoccum nigrum MF509753

Boeremia_exigua_KKX618486

Boeremia exigua KX618484

Boeremia_exigua_KX618485

Cryptosphaeria eunomia KX618490

Cryptosphaeria_eunomia_KX618491

Phomopsis sp. MF509748

Diaporthe_eres_MF509750

Phomopsis oblonga KX618489

Bionectriā_ochroleuca_MF509749

Fusarium oxysporum KX $\overline{6} 18492$

Fusarium_acumnatum_MF509746

Fusarium_avenaceum_MF509747

Hymenoscyphus fraxineus KY613994

Diplodia mutila_KX618487

Diplodia mutila KX618488

Paraphaeósphaería_neglecta_MF509754

Alternaria_alternata_MF509751

Alternaria_sp._MF509752

Pleosporales_sp.

Ascomycota_sp._KX 618493

Ascomycota_sp._KX618494

Epicoccum ñigrum MF509753

Boeremia_exigua_ǨK618486

Boeremia exigua KX618484

Boeremia_exigua_KX618485

Cryptosphaeria_eunomia_KX618490

Cryptosphaeria_eunomia_KX618491

Phomopsis sp. M $\mathrm{M} 509748$

Diaporthe_eres_MF509750

Phomopsis_oblonga_KX618489

Bionectriā_ochroleuca_MF509749

Fusarium_oxysporum_KX'̄18492

Fusarium_acumnatum_MF509746

Fusarium_avenaceum_MF509747

Hymenoscyphus fraxineus KY613994

Diplodia_muti $\bar{l} a \_K X 61848 \overline{7}$

Diplodia mutila_KX618488

Paraphaeosphaería_neglecta_MF509754

Alternaria_alternāta_MF509751

Alternaria_sp._MF509752

Pleosporales_sp._KX618495

Ascomycota sp. $\mathrm{kX} 618493$

Ascomycota_sp._KX618494


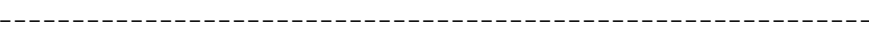
aagagctcttcacaccaagccagcccgggaaaccggctggtggcccattggaaaccatgg

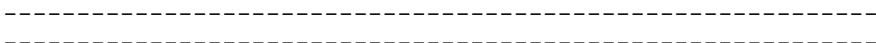

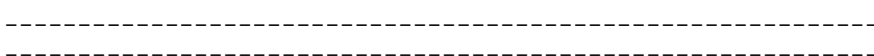

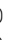
0 0 0 0

0 60 0 0 0 0 
Epicoccum_nigrum_MF509753 Boeremia_exigua KXX618486 Boeremia exigua KX618484 Boeremia_exigua_KX618485

Cryptosphaeria_eunomia_KX618490 Cryptosphaeria_eunomia_KX618491 Phomopsis sp. MF509748 Diaporthe_eres_MF509750 Phomopsis oblonga KX618489 Bionectriā_ochrolēuca_MF509749 Fusarium oxysporum KX $\overline{6} 18492$ Fusarium_acumnatum_MF509746 Fusarium_avenaceum_MF509747 Hymenoscyphus fraxineus KY613994 Diplodia_mutī̄a_KX618487 Diplodia mutila KX618488 Paraphaeōsphaería_neglecta_MF509754 Alternaria_alternāta_MF509751 Alternaria sp. MF509752 Pleosporales_sp._KX618495 Ascomycota sp. $\mathrm{KX} 618493$ Ascomycota_sp._KX618494 Epicoccum_nigrum_MF509753 Boeremia_exigua_KX618486 Boeremia_exigua_KX618484 Boeremia exigua KX618485

Cryptosphaeria eunomia KX618490 Cryptosphaeria_eunomia_KX618491 Phomopsis_sp._MF509748 Diaporthe eres MF509750 Phomopsis_oblonga_KX618489 Bionectriā ochroleuca_MF509749 Fusarium_oxysporum_KXб̄18492 Fusarium_acumnatum_MF509746 Fusarium avenaceum MF509747 Hymenoscyphus_fraxineus_KY613994 Diplodia_mutī̄a_KX618487 Diplodia_mutila_KX618488 Paraphaeosphaería_neglecta_MF509754 Alternaria_alternata_MF509751 Alternaria_sp._MF509752 Pleosporales sp. KX618495 Ascomycota_sp.. KX̄618493 Ascomycota sp. KX618494 Epicoccum_nigrum_MF509753 Boeremia_exigua_K̄X618486 Boeremia exigua KX618484 Boeremia_exigua_KX618485

Cryptosphaeria_eunomia_KX618490 Cryptosphaeria_eunomia_KX618491 Phomopsis sp. MF509748 Diaporthe_eres_MF509750 Phomopsis oblonga KX618489 Bionectriā_ochrolēuca_MF509749 Fusarium oxysporum KX $\overline{6} 18492$ Fusarium_acumnatum_MF509746 Fusarium_avenaceum_MF509747 Hymenoscyphus fraxineus KY613994 Diplodia_muti $\bar{l} a \_K X 61848 \overline{7}$ Diplodia mutila_KX618488 Paraphaeósphaería_neglecta_MF509754 Alternaria_alternäta_MF509751 Alternaria_sp. MF509752 Pleosporales_sp. Ascomycota sp. KX 618493 Ascomycota_sp._KX618494 Epicoccum_nigrum_MF509753 Boeremia_exigua_KX618486

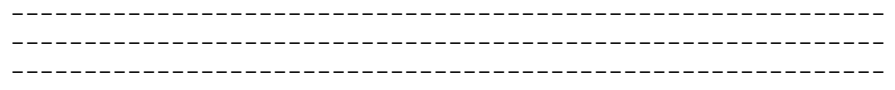

0

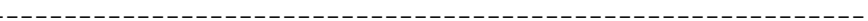

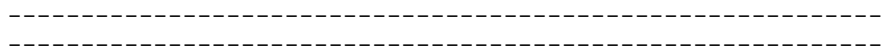

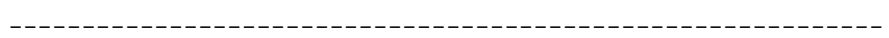

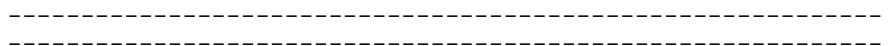

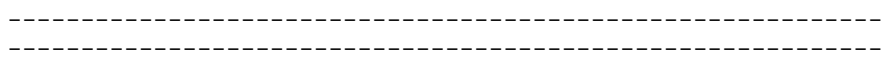

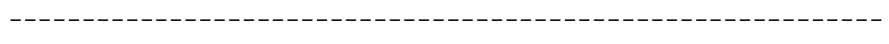

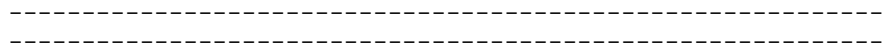
-

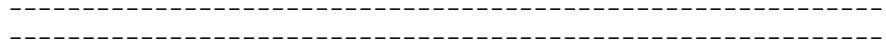
ggtacggtaacagttgaagagatgacccggccagccggtgaaatgggcgatccgcagcga

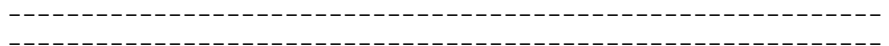

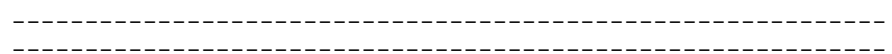
-

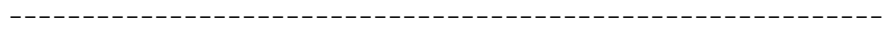

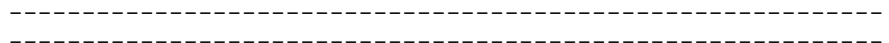

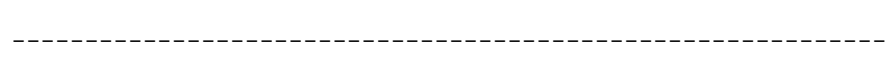

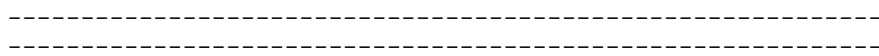



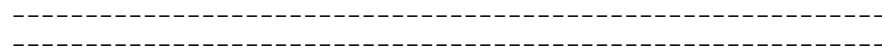

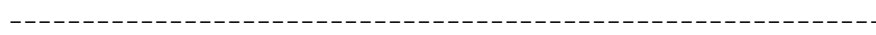

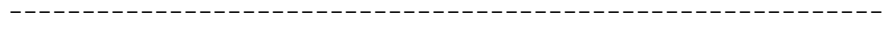
-


agcccttctgttggtggtagcagccttggccgcagccaaacatggggaacgttcacaga

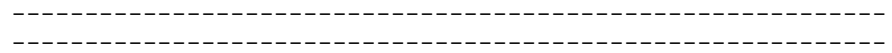



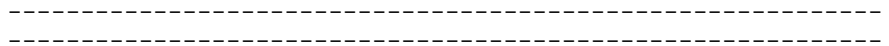
-

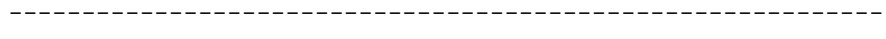
-

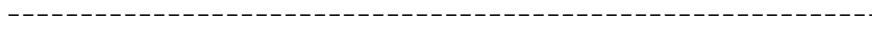

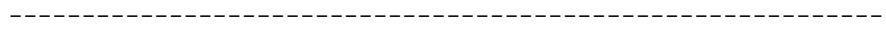
-

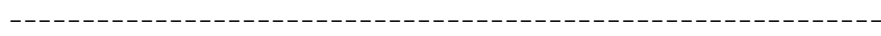
----




ctaagtggaagtgggtggggcctagccctgcttaagatatagtcgggccccttggaaac

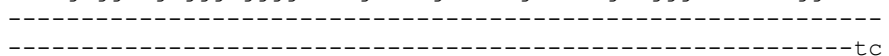

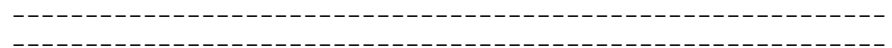
-

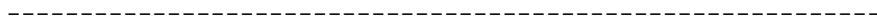
0 
Boeremia_exigua_KX618484

Boeremia exigua KX618485

Cryptosphaeria_eunomia_KX618490 Cryptosphaeria eunomia KX618491

Phomopsis_sp. $\bar{M} F 509748$

Diaporthe eres MF509750

Phomopsis oblonga KX618489

Bionectriā_ochroleuca_MF509749

Fusarium oxysporum KX 618492

Fusarium_acumnatum_MF509746

Fusarium avenaceum MF509747

Hymenoscyphus fraxineus KY613994

Diplodia_mutila_KX618487

Diplodia mutila KX618488

Paraphaeosphaería_neglecta_MF509754

Alternaria alternāta MF5097̄51

Alternaria_sp._MF509752

Pleosporalèes_sp.

Ascomycota sp. KX618493

Ascomycota_sp._KX618494

Epicoccum nigrum MF509753



Boeremia exigua KX618484

Boeremia exigua KX618485

Cryptosphaeria eunomia KX618490

Cryptosphaeria_eunomia_KX618491

Phomopsis sp. $\bar{M} F 509748$

Diaporthe eres MF509750

Phomopsis_oblonga KX618489

Bionectria ochroleuca MF509749

Fusarium_oxysporum_KX $\overline{6} 18492$

Fusarium acumnatum MF509746

Fusarium avenaceum MF509747

Hymenoscyphus fraxīneus KY613994

Diplodia mutīa KX618487

Diplodia_mutila_KX618488

Paraphaeōsphaería neglecta MF509754

Alternaria_alternāta MF5097̄51

Alternaria sp. MF509752

Pleosporales sp. KX618495

Ascomycota_sp. $\bar{p}$. KX 618493

Ascomycota sp. KX618494

Epicoccum_ñigrum MF509753

Boeremia exigua $\bar{K} X 618486$

Boeremia exigua KX618484

Boeremia exigua KX618485

Cryptosphaeria_eunomia_KX618490

Cryptosphaeria eunomia KX618491

Phomopsis sp. $\bar{M} F 509748$

Diaporthe eres MF509750

Phomopsis oblonga KX618489

Bionectriā_ochroleuca_MF509749

Fusarium oxysporum KX $\overline{6} 18492$

Fusarium_acumnatum_MF509746

Fusarium avenaceum MF509747

Hymenoscyphus fraxineus KY613994

Diplodia mutila KX618487

Diplodia mutila KX618488

Paraphaeōsphaería_neglecta_MF509754

Alternaria alternata MF509751

Alternaria sp. MF509752

Pleosporalès sp. KX618495

Ascomycota sp. KX618493

Ascomycota_sp._KX618494

Epicoccum ñigrum MF509753

Boeremia_exigua_-̄KX618486

Boeremia exigua KX618484

Boeremia_exigua_KX618485



0

ttccgtaggtgaacct

ttccgtaggtgaacct

-tcttggtcatttagaggaagtaa-----aagtcgtaacaaggtctccgttggtgaacca

-tcttggtcatttagaggaagtaa-----aagtcgtaacaaggtctccgttggtgaacca

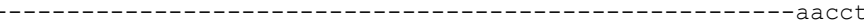

--cttggtcatttagaggaagtaa-----aagtcgtaacaaggtctccgttggtgaacca



--cttggtcatttagaggaagtaa-----aagtcgtaacaaggtctccgttggtgaacca --cttggtcatttagaggaagtaa-----aagtcgtaacaaggtctccgttggtgaacca

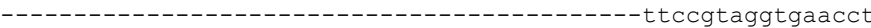

-------------------------------------cettccgtaggtgaacet

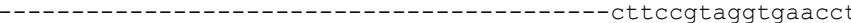

ttgggggggtgagttcggcctcctggccggctccaagcaaaccgttccgtaggtgaacct -gaggaagtaa-----aagtcgtaacaaggtctccgtaggtgaacct ttcttggtcatttagaggaagtaa-----aagtcgtaacaaggtctccgtaggtgaacct


--- - - - - - - - - - - - - - - - - -

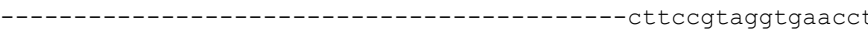

-tcttggtcatttagaggaagtaa-----aagtcgtaacaaggtttccgtaggtgaacct ----------------------------------------------------gaact

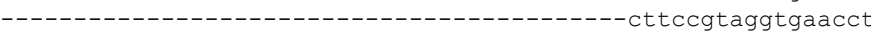

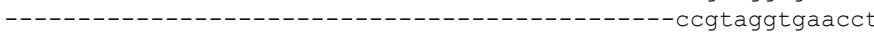
$\star \star \star \star$

gcggagggatcattacagagttatccaactcccaaacccatgtgaacttacctatgttgc gcggagggatcattacagagttatccaactcccaaacccatgtgaacttacctatgttgc gcggagggatcattgctggaacgcgccccaggcgcacccagaaaccctttgtgaacttat gcggagggatcattgctggaacgcgccccaggcgcacccagaaaccctttgtgaacttat gcggagggatcattgctggaacgcgccccaggcgcacccagaaaccctttgtgaacttat gcggagggatcattaccgagtttacaactcccaaacccatgtgaacatacctactgttgc gcggagggatcattaccgagtttacaactcccaaacccctgtgaacataccttaatgttg gcggagggatcattaccgagtttacaactcccaaacccctgtgaacataccttaatgttg gcggagggatcattaccgagtttacaactcccaaacccctgtgaacataccttaatgttg gcggaaggatcattacagagttcctgccctcacgggtagaaacccc-------------gcggaaggatcattaccgagttctcgagcttcggctcgaatctcccaccctttgtgaaca gcggaaggatcattaccgagttctcgagcttcggctcgaatctcccaccctttgtgaaca gcggaaggatcattatccatctcaaaccaggtgcggtcgcggcccccgggggcttgctcc gcggagggatcattaccaaatatgaaggcgggctggaacctct----------------gcggagggatcattaccaaatatgaaggcgggctggaacctct----------------gcggaaggatcattatccttttatcggagggttgatgccaatgctctgggctcatgctcg gcggaaggatcattaccaa---------------------------------------tt

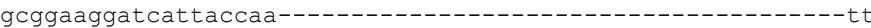
gcggaaggatcattaccta--------------------------------------ga gcggaaggatcattaccta---------------------------------------ga gcggaaggatcattaccta---------------------------------------ga gcggaaggatcattaccta------------------------------------ga

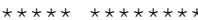

ctcggcggggaagcct-------acccggtacctaccetgtagctaccegggagcgaget ctcggcggggaagcct-------acccggtacctaccctgtagctacccgggagcgagct accttactgttgcctc-------ggcg-----------catgccggcccecttgggggcc accttactgttgcctc-------ggcg-----------catgccgg cecccetgggggec accttactgttgcctc-------ggcg----------ctagctg--gtccctcggggec



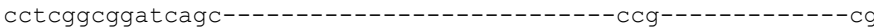
cetcggcggatcagc---------------------------ccg-------------cg cctcggcggatcagc--------------------------Ccg------------cg -----------------acccttgtgtatattatattgttgctttagcaggtcg ta------------------cctctgttgctttggcggctcttgccgcgtggaggcc ta-----------------cctctgttgctttggcggctcttgccgcgtggaggec cgggtggtaggggtaacacctgcacgcgccgcctgcctgtaccctcttttacgagcacc -cggggttaca-----------gccttgctgaattattcaccettgtcttttgcgta--cggggttaca-----------gccttgctgaattattcacccttgtcttttgcgta-gttcactggct-----------catctctttctgattctacccatgtttttgcgta-taatcggggga-----------cttcggtccetgtctgaaccettgtcttttgcgta-taatcggggga------------cttcggtccctgtctgaacccttgtcttttgcgta-gtttgtagact------------tcggtctgctacctcttacccatgtcttttgagta-gttgtaggctt-----------tg--cctaccatctcttacccatgtcttttgagta-gttgtaggctt-----------tg--cctaccatctcttacccatgtcttttgagta-gttgtaggctt-----------tg--cctaccatctcttacccatgtcttttgagta--
16 
Cryptosphaeria_eunomia_KX618490 Cryptosphaeria eunomia KX618491 Phomopsis sp. MF509748 Diaporthe_eres_MF509750 Phomopsis oblonga KX618489 Bionectriā_ochroleuca_MF509749 Fusarium_oxysporum_Kx $\overline{6} 18492$ Fusarium_acumnatum_MF509746 Fusarium_avenaceum_MF509747 Hymenoscyphus_fraxineus_KY613994 Diplodia_mutī̄a_KX618487 Diplodia mutila KX618488 Paraphaeōsphaería_neglecta_MF509754 Alternaria_alternāta_MF509751

Alternaria_sp. MF509752

Pleosporales sp. KX618495

Ascomycota sp. KX 618493 Ascomycota_sp._KX618494 Epicoccum nigrum MF509753 Boeremia_exigua_K̄X618486 Boeremia exigua KX618484 Boeremia_exigua_KX618485

Cryptosphaeria eunomia KX618490 Cryptosphaeria_eunomia_KX618491 Phomopsis sp. MF509748 Diaporthe_eres_MF509750 Phomopsis oblonga KX618489 Bionectriā_ochroleuca_MF509749 Fusarium_oxysporum_kX-̄ 18492 Fusarium_acumnatum_MF509746 Fusarium_avenaceum_MF509747 Hymenoscyphus_fraxineus_KY613994 Diplodia_mutil̄a_KX618487 Diplodia_mutila_KX618488 Paraphaeosphaería_neglecta_MF509754 Alternaria alternāta MF509751 Alternaria sp. MF509752 Pleosporales sp. KX618495 Ascomycota sp. KX 618493 Ascomycota_sp._KX618494 Epicoccum nigrum MF509753 Boeremia_exigua_K̄X618486 Boeremia exigua KX618484 Boeremia_exigua_KX618485

Cryptosphaeria eunomia KX618490 Cryptosphaeria_eunomia_KX618491 Phomopsis sp. MF509748 Diaporthe_eres_MF509750 Phomopsis_oblonga_KX618489 Bionectrià ochroleuca MF509749

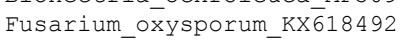
Fusarium acumnatum MF509746 Fusarium_avenaceum_MF509747 Hymenoscyphus fraxineus KY613994 Diplodia_muti $\bar{l} a$ KX618487 Diplodia mutila KX618488 Paraphaeosphaería neglecta MF509754 Alternaria_alternata_MF509751 Alternaria sp. MF5097̄52 Pleosporales_sp. Ascomycota_sp..$\overline{\mathrm{X}} 618493$ Ascomycota_sp._KX618494 Epicoccum nigrum MF509753 Boeremia éxigua_K̄X618486 Boeremia exigua KX618484 Boeremia exigua KX618485 accctgtagcc---cgetgcaggectacccgccggtggacgattaaactcttgttttta accctgtagcc---cgctgcaggcctacccgccggtggacgattaaactcttgtttttta cctctcctg--------gaggagcaggcacgccggcggccaacctaactcttgtttttac cctcacccco---ggtgttgagacagcccgccggcggccaacccaactcttgtttttac cctcaccctcg---ggtgttgagacagcccgtcggcggccaacctaactcttgtttttac cgcctcgtgtg---ccccggatcaggcgcccgcctaggaaacttaattcttgttttattt cccegtaaa---------acgggacggeccgccagaggacccaaactctaatgtttctta ccccgtaaa---------acgggacggcccgccagaggacccaaactctaatgtttctta ccccgtaaa--------acgggacggcccgccagaggacccaaactctaatgtttctta c----cctctgggcgtcggcctcggc-tgactgtgcctgctagaggaccctaattttga ctcaaaaagccccccc----gtgcgc-ttccgccagaggaccttcaaactccagtcagta ctcaaaaagcccccc----gtgcgc-ttccgccagaggaccttcaaactccagtcagta tttcgttctccttcggcggggcaacctgccgctggaaccaaaacaaaaccttttttgcat cttcttgtttccttggtgggttcgcccacca----ctaggacaaacataaaccttttgta cttcttgtttccttggtgggttcgcccacca----ctaggacaaacataaaccttttgta ctacttgtttccttggtgggcttgcctacca----ataggacatattaaaaccttttgta ctagttgtttcctcggtaggcttgcctgccg---gttggacagtaaaaaaactttt-gt ctagttgtttcctcggtaggcttgcctgccg---gttggacagtaaaaaacctttt-gt cct-tcgtttcctcggcgggtccgcccgccg---attggacaacattcaaaccetttgca cct-tcgtttcctcggcgggtccgcccgccg---attgga-caaacttaaaccetttgta cct-tcgtttcctcggcgggtccgcccgccg---attgga-caaacttaaaccctttgta cct-tcgtttcctcggcgggtccgcccgccg---attgga-caaacttaaaccctttgta

gtggattatctgagtgtttatacttaataagttaaactttcaacaacggatctcttggt gtggattatctgagtgtttatacttaataagttaaactttcaacaacggatctcttggt actgaaactctgagaataaacataaatgaatcaaaactttcaacaacggatctcttggt actgaaactctgagaataaacataaatgaatcaaactttcaacaacggatctcttggt actgaaactctgagcacaaacataaatgaatcaaactttcaacaacggatctcttggt tggaatcttctgagtagtttttacaaataaataaaactttcaacaacggatctcttggt ttgtaacttctgagtaaacaaacaaataaatcaaactttcaacaacggatctcttggt ttgtaacttctgagtaaacaaacaaataaatcaaactttcaacaacggatctcttggt ttgtaacttctgagtaaacaaacaaataaatcaaactttcaacaacggatctcttggt aatacagtgtcgtctgagtactatttaatagttaaactttcaacaacggatctcttggt aacgtcgacgtctgaaaacaagttaataaactaaactttcaacaacggatctcttggt aacgtcgacgtctgaaaacaagttaataaactaaactttcaacaacggatctcttggt ctagcattacctgttctgatacaaacaatcgttacaactttcaacaatggatctcttggc attgcaatcagcgtcagtaacaaattaataattacaactttcaacaacggatctcttggt attgcaatcagcgtcagtaacaaattaataattacaactttcaacaacggatctcttggt attgcagtcagcgtcagtaacaatgtaataattacaactttcaacaacggatctcttggt aattgcaatcagcgtcagaaaacataatagttacaactttcaacaacggatctcttggt aattgcaatcagcgtcagaaaacataatagttacaactttcaacaacggatctcttggt gttgcaatcagcgtctgaaaaacataatagttacaactttcaacaacggatctcttggt attgaaatcagcgtctgaaaaacataatagttacaactttcaacaacggatctcttggt attgaaatcagcgtctgaaaaacataatagttacaactttcaacaacggatctcttggt attgaaatcagcgtctgaaaaacataatagttacaactttcaacaacggatctcttggt

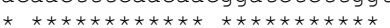

tctggcatcgatgaagaacgcagcgaaatgcgataagtaatgtgaattgcagaattcagt tctggcatcgatgaagaacgcagcgaaatgcgataagtaatgtgaattgcagaattcagt tctggcatcgatgaagaacgcagcgaaatgcgataagtaatgtgaattgcagaattcagt tctggcatcgatgaagaacgcagcgaaatgcgataagtaatgtgaattgcagaattcagt tctggcatcgatgaagaacgcagcgaaatgcgataagtaatgtgaattgcagaattcagt tctggcatcgatgaagaacgcagcgaaatgcgataagtaatgtgaattgcagaattcagt tctggcatcgatgaagaacgcagcaaatgcgataagtaatgtgaattgcagaattcagt tctggcatcgatgaagaacgcagcaaaatgcgataagtaatgtgaattgcagaattcagt tctggcatcgatgaagaacgcagcaaatgcgataagtaatgtgaattgcagaattcagt tctggcatcgatgaagaacgcagcgaaatgcgataagtaatgtgaattgcagaattcagt tctggcatcgatgaagaacgcagcgaaatgcgataagtaatgtgaattgcagaattcagt tctggcatcgatgaagaacgcagcgaaatgcgataagtaatgtgaattgcagaattcagt tctggcatcgatgaagaacgcagcgaaatgcgataagtagtgtgaattgcagaattcagt tctggcatcgatgaagaacgcagcgaaatgcgataagtagtgtgaattgcagaattcagt tctggcatcgatgaagaacgcagcgaaatgcgataagtagtgtgaattgcagaattcagt tctggcatcgatgaagaacgcagcgaaatgcgataagtagtgtgaattgcagaattcagt tctggcatcgatgaagaacgcagcgaaatgcgaaaagtagtgtgaattgcagaattcagt tctggcatcgatgaagaacgcagcgaaatgcgaaaagtagtgtgaattgcagaattcagt tctggcatcgatgaagaacgcagcgaaatgcgataagtagtgtgaattgcagaattcagt tctggcatcgatgaagaacgcagcgaaatgcgataagtagtgtgaattgcagaattcagt tctggcatcgatgaagaacgcagcgaaatgcgataagtagtgtgaattgcagaattcagt tctggcatcgatgaagaacgcagcgaaatgcgataagtagtgtgaattgcagaattcagt

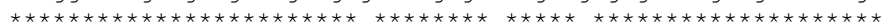

186 
Cryptosphaeria_eunomia_KX618491 Phomopsis_sp. $\bar{M}$ F509748 Diaporthe eres MF509750 Phomopsis_oblonga_KX618489 Bionectriā ochrolēuca MF509749 Fusarium_oxysporum_KX'̄ 18492 Fusarium_acumnatum_MF509746 Fusarium_avenaceum_MF509747 Hymenoscyphus_fraxineus KY613994 Diplodia muti $\bar{l} a$ KX618487 Diplodia_mutila_KX618488 Paraphaeosphaería neglecta MF509754 Alternaria_alternāta_MF509751 Alternaria sp. MF509752 Pleosporales_sp._KX618495 Ascomycota_sp._KX̄618493 Ascomycota sp. KX618494 Epicoccum_nigrum_MF509753 Boeremia exigua KX618486 Boeremia_exigua_KX618484 Boeremia_exigua_KX618485

Cryptosphaeria eunomia KX618490 Cryptosphaeria eunomia_KX618491 Phomopsis_sp._MF509748 Diaporthe eres MF509750 Phomopsis_oblonga_KX618489 Bionectriā ochroleuca MF509749 Fusarium_oxysporum_KX618492 Fusarium_acumnatum_MF509746 Fusarium_avenaceum_MF509747 Hymenoscyphus fraxineus KY 613994 Diplodia mutila KX618487 Diplodia mutila KX618488 Paraphaeosphaería neglecta MF509754 Alternaria_alternata_MF509751 Alternaria_sp. MF509752 Pleosporales sp. KX618495 Ascomycota_sp. KX̄618493 Ascomycota sp. KX618494 Epicoccum_nigrum_MF509753 Boeremia_exigua_K̄X618486 Boeremia_exigua_KX618484 Boeremia_exigua_KX618485

Cryptosphaeria_eunomia_KX618490 Cryptosphaeria_eunomia_KX618491 Phomopsis_sp._MF509748 Diaporthe eres MF509750 Phomopsis_oblonga_KX618489 Bionectriā_ochroleuca MF509749 Fusarium_oxysporum_KX618492 Fusarium acumnatum MF509746 Fusarium avenaceum MF509747 Hymenoscyphus_fraxineus_KY613994 Diplodia mutila KX618487 Diplodia_mutila_KX618488 Paraphaeosphaeria neglecta MF509754 Alternaria_alternata_MF509751 Alternaria_sp._MF509752 Pleosporales sp. KX618495 Ascomycota_sp. Ascomycota sp. KX618494 Epicoccum_nigrum_MF509753 Boeremia exigua KX K618486 Boeremia_exigua_KX618484 Boeremia_exigua_KX618485 gaatcatcgaatctttgaacgcacattgcgcccattagtattctagtgggcatgcctgtt gaatcatcgaatctttgaacgcacattgcgccctctggtattccggagggcatgcctgtt gaatcatcgaatctttgaacgcacattgcgccctctggtattccggagggcatgcctgtt gaatcatcgaatctttgaacgcacattgcgccctctggtattccggagggcatgcctgtt gaatcatcgaatctttgaacgcacattgcgcccgccagtattctggcgggcatgcctgtc gaatcatcgaatctttgaacgcacattgcgcccgctggtattccggcgggcatgcctgtt gaatcatcgaatctttgaacgcacattgcgcccgctggtattccggcgggcatgcctgtt gaatcatcgaatctttgaacgcacattgcgcccgctggtattccggcgggcatgcctgtt gaatcatcgaatctttgaacgcacattgcgccccttggtattccggggggcatgcctgtt gaatcatcgaatctttgaacgcacattgcgccccttggcattccgaggggcatgcctgtt gaatcatcgaatctttgaacgcacattgcgccccttggcattccgaggggcatgcctgtt gaatcatcgaatctttgaacgcacattgcgccccttggtattccatggggcatgcctgtt gaatcatcgaatctttgaacgcacattgcgccctttggtattccaaagggcatgcctgtt gaatcatcgaatctttgaacgcacattgcgccctttggtattccaaagggcatgcctgtt gaatcatcgaatctttgaacgcacattgcgccccttggtattccatggggcatgcctgtt gaatcatcgaatctttgaacgcacattgcgccccttggtattccatggggcatgcctgtt gaatcatcgaatctttgaacgcacattgcgccccttggtattccatggggcatgcctgtt gaatcatcgaatctttgaacgcacattgcgccccttggtattccatggggcatgcctgtt gaatcatcgaatctttgaacgcacattgcgccccttggtattccatggggcatgcctgtt gaatcatcgaatctttgaacgcacattgcgccccttggtattccatggggcatgcctgtt gaatcatcgaatctttgaacgcacattgcgccccttggtattccatggggcatgcctgtt

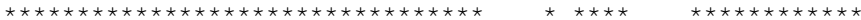

cgagcgtcatttcgaccattcaagccctggttgcttggtgttgggagcttgtcctc---cgagcgtcatttcgaccattcaagccctggttgcttggtgttgggagcttgtcctc---cgagcgtcatttcaaccctcaagcctggcttggtgatggggcactgcctgtaa------cgagcgtcatttcaaccctcaagcctggcttggtgatggggcactgcttcttaccc---cgagcgtcatttcaaccctcaagcctggcttggtgatggggcactgcttcttaccc---tgagcgtcatttcaaccctcatgcccctagggcgtggtgttggggatcggccaaagcccg cgagcgtcatttcaaccctcaagcccccgggtttggtgttggggat-cggctctgc--ct cgagcgtcatttcaaccctcaagcccccgggtttggtgttggggat-cggctctgccctt cgagcgtcatttcaaccctcaagcccccgggtttggtgttggggat-cggctctg--cct cgagcgtcatttagaccaactcccgctccggcggggtcttgggctgcgcctttgggcggg cgagcgtcattacaaccctcaagctctgcttggtattgggcgacgtcctctctgcggacg cgagcgtcattacaaccctcaagctctgcttggtattgggcgacgtcctctctgcggacg cgagcgtcatctacaccctcaagctctgcttggtgttgggcgtctgtcccgcctctgcgc cgagcgtcatttgtaccctcaagctttgcttggtgttgggcgtcttgtctctagct---cgagcgtcatttgtaccctcaagctttgcttggtgttgggcgtcttgtctctagct---cgagcgtcatttgtaccctcaagcactgcttggtgttgggtgtatgttttccttgcgct cgagcgtcatttgtaccttcaagctctgcttggtgttgggtgtttgtccccgcgttatgc cgagcgtcatttgtaccttcaagctctgcttggtgttgggtgtttgtccccgcgttatgc cgagcgtcatttgtaccttcaagctctgcttggtgttgggtgtttgtctcgcctctgcgt cgagcgtcatttgtaccttcaagctctgcttggtgttgggtgtttgtctcgcctctgcgt cgagcgtcatttgtaccttcaagctctgcttggtgttgggtgtttgtctcgcctctgcgt cgagcgtcatttgtaccttcaagctctgcttggtgttgggtgtttgtctcgcctctgcgt



---------ggacaactcctcaaaagcattggcggagtcgcggtggcccca--agcgtag --------ggacaactcctcaaaagcattggcggagtcgcggtggcccca--agcgtag -----aa--gggcaggccctgaaattcagtggcgagctcgccaggaccccg--agcgcag ----aag--gagcaggccctgaaattcagtggcgagctcgccaggaccccg--agcgcag ----aag--aagcaggccctgaaattcagtggcgagctcgccaggaccccg--agcgcag cgaggga--cggccggcccctaaatctagtggcggacccgtcgtggcctcctctgcgaag cacggcg--gtgccgcccccgaaatacattggcggtctcgctgcagcctccattgcgtag ctgggcg--gtgccgcccccgaaatacattggcggtctcgctgcagcctccattgcgtag tctggcg--gtgccgcccccgaaatacattggcggtctcgctgcagcctccattgcgtag ccttaaaac---------------cagtggcggtgccctaaggctctacgcgtagtaa cgcctcaaagacctcggcggtggetgttcagccctcaagcgtagtag------aatacac cgcctcaaagacctcggcggtggctgttcagccctcaagcgtagtag------aatacac --------gcggactcgcccaaattcattggcagcggtctttgcctcctct-cgcgcag ---ttgctggagactcgccttaaagtaattggcagccggcctactggtttcggagcgcag ---ttgctggagactcgccttaaagtaattggcagccggcctactggtttcggagcgcag gcgtaagtgaggactcgccttaaaacaattggcagccggcatattggcctgg-agcgcag --------gcggactcgcctcaaagcaattggcagccngcgtactggccttggagcgcag --------gcggactcgcctcaaagcaattggcagccggcgtactggccttggagcgcag --------gtagactcgccttaaaacaattggcagccggcgtattgatttcggagcgcag -------gtagactcgccttaaaacaattggcagccggcgtattgatttcggagcgcag --------gtagactcgccttaaaacaattggcagccggcgtattgatttcggagcgcag --------gtagactcgccttaaaacaattggcagccggcgtattgatttcggagcgcag

$$
\star \star
$$

taattcttctcgcttccggtgtgtcacggctggcgtctggccgttaaacccccccatttt taattcttctcgcttccggtgtgtcacggctggcgtctggccgttaaacccccccatttt 
Phomopsis_sp._MF509748

Diaporthe eres MF509750

Phomopsis oblonga KX618489

Bionectriāochroleuca_MF509749

Fusarium oxysporum Kx̄̄18492

Fusarium_acumnatum_MF509746

Fusarium_avenaceum_MF509747

Hymenoscyphus_fraxineus_KY613994

Diplodia_mutila_KX618487

Diplodia mutila KX618488

Paraphaeōsphaerīa_neglecta_MF509754

Alternaria alternāta MF509751

Alternaria_sp._MF509752

Pleosporales sp. KX618495

Ascomycota_sp._KX618493

Ascomycota sp. KX618494

Epicoccum ñigrum MF509753

Boeremia_exigua_KX618486

Boeremia exigua KX618484

Boeremia exigua_KX618485

Cryptosphaeria_eunomia_KX618490

Cryptosphaeria eunomia KX618491

Phomopsis sp. MF509748

Diaporthe_eres_MF509750

Phomopsis oblonga KX618489

Bionectriā_ochroleuca_MF509749

Fusarium oxysporum KX̄̄18492

Fusarium acumnatum_MF509746

Fusarium_avenaceum_MF509747

Hymenoscyphus fraxineus KY613994

Diplodia_mutila_KX618487

Diplodia mutila KX618488

Paraphaeosphaería_neglecta_MF509754

Alternaria alternata MF509751

Alternaria sp. MF50975 52

Pleosporales sp. KX618495

Ascomycota sp. KX 618493

Ascomycota sp. KX618494

Epicoccum ñigrum MF509753

Boeremia_exigua_K̄X618486

Boeremia exigua KX618484

Boeremia_exigua_KX618485

Cryptosphaeria eunomia KX618490

Cryptosphaeria_eunomia_KX618491

Phomopsis sp. $\bar{M}$ F509748

Diaporthe eres MF509750

Phomopsis oblonga KX618489

Bionectriāochroleuca_MF509749

Fusarium_oxysporum_KX̄̄18492

Fusarium_acumnatum_MF509746

Fusarium avenaceum MF509747

Hymenoscyphus fraxineus KY613994

Diplodia_mutī̄a_KX618487

Diplodia mutila KX618488

Paraphaeosphaería_neglecta_MF509754

Alternaria alternata MF509751

Alternaria sp. MF509752

Pleosporales sp. KX618495

Ascomycota sp. KX618493

Ascomycota_sp._KX618494

Epicoccum ñigrum MF509753

Boeremia_exigua_KXX618486

Boeremia exigua KX618484

Boeremia_exigua_KX618485 tagttaaaccetcgctc--tggaaggccetggcggtgccctgccgttaaaccccaactt tagttaaacctcgctc--tggaaggccctggcggtgccetgccgttaaaccccaact tagttaaaccctcgctc--tggaaggccctggcggtgccctgccgttaaaccccaactt tagtgatattccgcat------cggagagcgacgagcccetgccegttaaaccccaact tagctaacacctcgca------actggaacgcggegcggccatgccgtaaaaccccaact tagctaacacctcgca------actggaacgcggcgcggccatgccgtaaaaccccaact tagctaacacctcgca------actggaacgcggcgcggccatgccgtaaaaccccaact tt---------cttctcgcg--atagggtccttgcggtgtcttgccagcaaccccaact ct---------cgctttggagcggttg-gcgtcgcccgccggacgaaccttctgaacttt ct---------cgctttggagcggttg-gcgtcgcccgccggacgaaccttctgaacttt ca---------caattgcgtctgcgg---gggggcgtggcccgcgtccacgaagcaacat ca--------caagtcgcactctctatcagcaaaggtctagcatccattaagccttttt ca---------caagtcgcactctctatcagcaaaggtctagcatccattaagccttttt ca---------cattttgcgcctcttgtca-tga-ttgttggcatccatcaagacctttt ca--------cattttgcgcccetcagcttgaa-cgcttgcgtccattaagcctacaat ca--------cattttgcgcccctcagcttgaa-cgcttgcgtccattaagcctacaat ta---------catctcgcgctttgcactcacaa-cgacga--cgtccaaaagtacattt ta---------catctcgcgctttgcactcataa-cgacga--cgtccaaaaagtacttt ta--------catctcgcgctttgcactcataa-cgacga--cgtccaaaagtacttt ta---------catctcgcgctttgcactcataa-cgacga--cgtccaaaaagtacttt

tcagtggtttgacctcggatcaggtaggaatacccgctgaacttaagcatatcaataagc tcagtggtttgacctcggatcaggtaggaatacccgctgaacttaagcatatcaata--ctgaaaatttgacctcggatcaggtaggaatacccgctgaacttaagcatatcaataagc ctgaaaatttgacctcggatcaggtaggaatacccgctgaacttaagcatatcaataagc ctgaaaatttgacctcggatcaggtaggaatacccgctgaacttaagcatatcaata--ttccaaggttgacctcagatcaggtaggaatacccgctgaacttaagcatatcaataagc tctgaatgttgacctcggatcaggtaggaatacccgctgaacttaagcatatcaataagc tctgaatgttgacctcggatcaggtaggaatacccgctgaacttaagcatatcaataagc tctgaatgttgacctcggatcaggtaggaatacccgctgaacttaagcatatcaataagc ctctagggttgacctcggatcaggtagggatacccgctgaacttaagcatatcaataagc tctcaaggttgacctcggatcaggtagggatacccgctgaacttaagcatatcaata--tctcaaggttgacctcggatcaggtagggatacccgctgaacttaagcatatcaataagc taccgtctttgacctcggatcaggtagggatacccgctgaacttaagcatatcat----ttcaacttttgacctcggatcaggtagggatacccgctgaacttaagcatatcaat---ttcaacttttgacctcggatcaggtagggatacccgctgaacttaagcatatcaataagc attagctcttgacctcggatcaggtagggatacccgctgaacttaagcatatcaataagc ttttgctcttgacctcggatcaggtagggatacccgctgaacttaagcatatcaataagc ttttgctcttgacctcggatcaggtagggatacccgctgaacttaagcatatcaataagc ttacactcttgacctcggatcaggtagggatacccgctgaacttaagcatatcaataagc ttacactcttgacctcggatcaggtagggatacccgctgaacttaagcatatcaataagc ttacactcttgacctcggatcaggtagggatacccgctgaacttaagcatatcaataagc ttacactcttgacctcggatcaggtagggatacccgctgaacttaagcatatcaata---

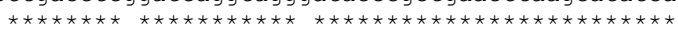

ggagga- 597

----- 588

ggaggaa $\quad 617$

ggaggaa $\quad 626$

-------

ggagga- 608

ggagga- $\quad 562$

ggaggaa $\quad 602$

ggaggaa 600

ggagga- 552

----- 573

ggagga- 581

----- 994

------ 585

ggaggaa $\quad 612$

ggaggaa $\quad 594$

ggagga- 545

ggagga- 548

ggaggaa $\quad 584$

ggagga- 532

ggaggaa $\quad 544$

---n-- 531 